\title{
Gir tidligere aborter fødselsangst?
}

\begin{abstract}
BAKGRUNN Abort angår mange kvinner, og man vet lite om følgene av slike erfaringer for senere graviditeter. Hensikten med studien var å undersøke om tidligere aborthistorie har betydning for utvikling av fødselsangst, justert for kvinnens psykiske helse, paritet, tidligere dødfødsler og sosiodemografiske faktorer.
\end{abstract}

MATERIALE OG METODE Studien omfattet 2753 gravide kvinner fra Akershus universitetssykehus. Informasjon ble innhentet ved hjelp av spørreskjemaer i svangerskapsuke 18 og 32 , samt ved uttrekk fra sykehusets fødejournalsystem. Angst for å føde ble målt ved Wijmaskalaen (W-DEQ).

RESULTATER Forekomsten av angst for å føde (definert som $\mathrm{W}$-DEQ $\geq 85$ ) var $11,7 \%$ blant kvinnene som hadde fått utført to eller flere selvbestemte aborter og 7,8 \% blant dem som aldri hadde tatt abort. Denne trenden var ikke statistisk signifikant og forsvant helt i de justerte analysene. Vi fant heller ingen sammenheng mellom spontanaborter og angst for å føde. Kvinnens psykiske helse var den faktoren som var sterkest assosiert med fødselsangst, en assosiasjon som vi også har funnet tidligere ved analyser av en mindre andel av kohorten.

FORTOLKNING Vi fant ingen samvariasjon mellom tidligere aborthistorie og fødselsangst.

Studier antyder at $5-20 \%$ av alle kvinner har sterk uro eller frykt for å føde $(1,2)$, og mange elektive keisersnitt gjøres i dag på indikasjonen fødselsangst (1-3). Angst under svangerskapet er blitt relatert til en rekke negative følger, slik som langvarig fødsel $(4,5)$, økt behov for smertestillende midler, og økt risiko for keisersnitt $(6,7)$. Frykt for svangerskap og fødsel har nok eksistert til alle tider, men innen forskningslitteraturen må dette sies å være et relativt nytt tema, og vi vet fortsatt lite om mekanismene bak denne frykten. Faktorer som tidligere obstetriske komplikasjoner hos flergangsfødende (8-10), frykt for smerte, sykdommer eller fysiske plager kan ha betydning for utvikling av fødselsangst, men også psykososiale faktorer og tidligere seksuelle overgrep $(11,12)$. Både spontanabort og selvbestemt abort kan for noen kvinner oppleves som traumatisk (13). Som oftest er slike mentale reaksjoner av kort varighet (14). Det er imidlertid mulig at et nytt svangerskap kan gjenoppfriske et traume. Det er derfor av interesse å undersøke hvorvidt tidligere aborthistorie kan spille en rolle med hensyn til utvikling av fødselsangst.

I 2011 ble det utført 15343 svangerskapsavbrudd i Norge. Omtrent hvert femte svangerskap ender med selvbestemt abort (15). Ca. $50 \%$ av alle påbegynte og $10-20 \%$ av klinisk registrerte graviditeter ender som spontanabort (16). Tidligere studier har vist at både spontanabort og selvbestemt abort er assosiert med økt risiko for angst og depresjon $(17,18)$. Det er også vist at kvinner som har tatt abort, har høyere risiko for å føle skyld og skam sammenliknet med kvinner som har opplevd spontanbort (17). En systematisk oversikt fra 2011 kunne imidlertid ikke bekrefte en sammenheng mellom selvbestemt abort og dårlig psykisk helse (19). Utfallsmål i denne oversiktsstudien var depresjon, angstlidelser, posttraumatisk stresslidelse og selvmord (19). Det er heller ikke gitt at kvinner med fødselsangst har dårlig psykisk helse. I en fersk norsk undersøkelse hadde majoriteten av kvinner med fødselsangst verken angst eller depresjon (20). Kvinner som i utgangspunktet var plaget av angst eller depresjon hadde imidlertid en økt risiko for fødselsangst, særlig hvis de var plaget av både angst og depresjon samtidig (20).

Så vidt vi vet, har ingen tidligere studier undersøkt sammenhengen mellom aborthistorie og fødselsangst. Hensikten med denne studien er derfor å studere hvilken betydning tidligere aborter har for utviklingen av fødselsangst, kontrollert for psykisk helsestatus, paritet, tidligere dødfødsler og sosiodemografiske faktorer.

\section{Materiale og metode \\ Metode og utvalg}

Datamaterialet er hentet fra studien Favn om fødselen, som er en kohortstudie av gravide ved Akershus universitetssykehus (10, 20, 21). Datainnsamlingen foregikk fra november 2008 til april 2011. Kvinnene ble rekruttert $\mathrm{i}$ forbindelse med rutineultralydundersøkelse i svangerskapsuke 17-20. Totalt kom 6244 kvinner til ultralyd i den aktuelle perioden. 152 kvinner ønsket ikke å delta. Ytterligere 1088 kvinner behersket ikke

\section{Tone Breines Simonsen}

tone.breines.simonsen@ahus.no

Forskningssenteret $\mathrm{H} \emptyset \mathrm{KH}$

Akershus universitetssykehus

og

Kvinneklinikken

Akershus universitetssykehus

og

Avdeling for helsefag

Institutt for helse og samfunn

Det medisinske fakultet

Universitetet i Oslo

\section{Astrid Klopstad Wah}

Avdeling for helsefag

Institutt for helse og samfunn

Det medisinske fakultet

Universitetet i Oslo

\section{Siri Vangen}

Nasjonalt kompetansesenter for kvinnehelse Oslo universitetssykehus, Rikshospitalet

og

Divisjon for epidemiologi

Nasjonalt folkehelseinstitutt

\section{Malin Eberhard-Gran}

Divisjon for psykisk helse

Nasjonalt folkehelseinstitutt

Forskningssenteret $\mathrm{H} \emptyset \mathrm{KH}$

Akershus universitetssykehus

> Se også side 606

\section{HOVEDBUDSKAP}

$8 \%$ av kvinnene rapporterte angst for å føde

Det var ingen samvariasjon mellom tidligere aborthistorie og utvikling av fødselsangst

Psykisk helse var den faktoren som viste sterkest samvariasjon med angst for å føde 


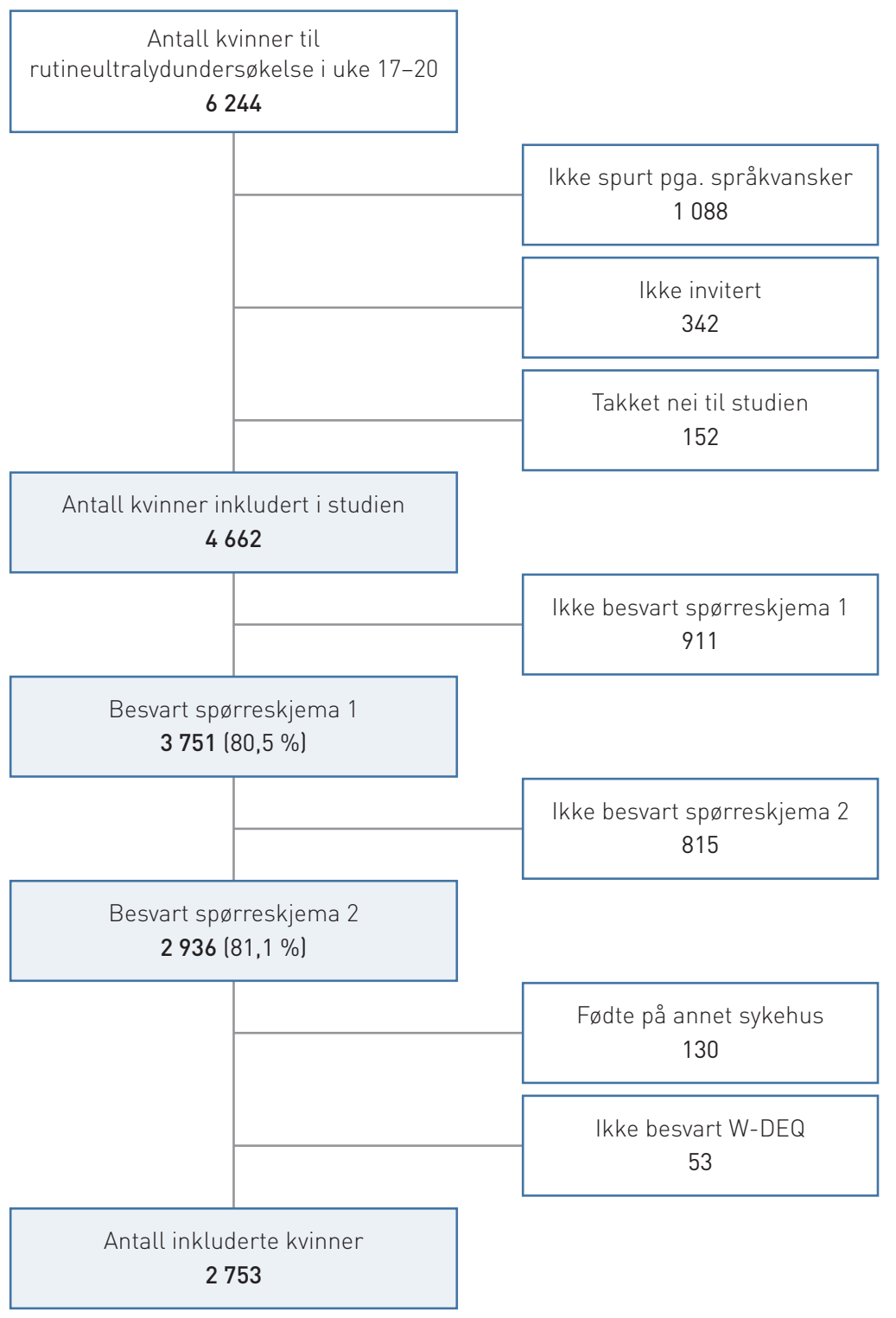

Figur 1 Oversikt over inkluderte kvinner i studien

norsk godt nok til å fylle ut et spørreskjema, og ble derfor ikke invitert til å delta i studien. 342 kvinner ble ikke invitert fordi jordmor eller lege glemte å spørre vedkommende, eller fordi spørsmål om prosjektdeltakelse ikke var på sin plass da ultralydundersøkelsen ga mistanke om patologiske forhold. Totalt ble 4662 kvinner inkludert i hele kohorten (fig 1). Data ble innsamlet ved hjelp av to spørreskjemaer. $80 \%$ av kvinnene som samtykket til deltakelse, besvarte spørreskjema 1 utdelt i uke 18. Dette skjemaet inneholdt bl.a. spørsmål om reproduktiv historie. Spørreskjema 2 ble tilsendt i uke 32 til dem som hadde besvart spørreskjema 1 , og inneholdt bl.a. spørsmål om angst/ depresjon samt fødselsangst. Av dem som fikk tilsendt dette skjemaet, svarte $81 \%$ (63\% av alle kvinner inkludert i studien). I tillegg ble det gjort et datauttrekk fra det elektroniske fødejournalsystemet (Partus). Totalt har vi informasjon fra 2753 gravide leder (M E-G). Deretter ble skjemaet oversatt tilbake til engelsk av en forsker på Folkehelseinstituttet med engelskspråklig bakgrunn. Skjemaet ble så sammenliknet med den engelske versjonen i tillegg til den originale svenske utgaven $(20,22)$.

Uavhengige variabler. Hovedforklaringsvariabler var tidligere spontanaborter og provoserte aborter.

- Spørsmålene om spontanaborter var formulert slik: Har du noen gang opplevd ufrivillig abort (ja/nei)? Hvor mange ganger? Svarene ble kodet «aldri/ 1 gang/ 2 eller flere ganger».

- Spørsmålene om selvbestemt abort var formulert slik: Har du noen gang tatt abort (ja/ nei)? Hvor mange ganger? Svarene ble kodet «aldri/ 1 gang/ 2 eller flere ganger».

For å kunne ta stilling til i hvilken grad vårt utvalg er representativt $\mathrm{i}$ forhold til den generelle populasjonen av fødende kvinner på sykehuset, ble andelen rapporterte aborter i Favn om fødselen-studien sammenliknet med andelen registrerte aborter i sykehusets elektroniske fødejournaler (Partus).

Kontrollvariabler. Symptomer på depresjon gjennom siste uke ble målt $i$ svangerskapsuke 32 ved hjelp av The Edinburgh Postnatal Depression Scale (EPDS) (23, 24). EPDS er en vurderingskala som består av ti spørsmål, designet for å oppdage symptomer på depresjon etter fødsel. Summen på hele skalaen varierer fra 0 til 30, der høy skår indikerer depresjon. Basert på funn fra tidligere undersøkelser ble depresjon definert som en skår på 12 eller mer $(23,24)$. Den norske versjonen er validert opp mot DSM-IV-kriterier (Diagnostic and Statistical Manual of Mental Disorders) for alvorlig depresjon (25). Symptomer på angst gjennom siste uke ble målt $\mathrm{i}$ svangerskapsuke 32 ved hjelp av The Hopkins Symptom Check List (SCL-25). SCL-25 er en selvvurderingsskala, hvor de første ti påstander omfatter angstsymptomer. Summen på hele skalaen for angstspørsmålene varierer fra minimum 10 til maksimum 40, der høy skår indikerer angst. Basert på funn fra tidligere undersøkelser ble så nærvær av angst definert som en skår på 18 eller mer på SCL-angstskalaen (26-28). Den norske versjonen av SCL er validert opp mot ICD-10kriterier for angst og depresjon (29). Psykisk helse ble kodet: «Verken angst eller depresjon / angst / depresjon/ både angst og depresjon».

Andre variabler som ble inkludert var alder, sivilstand, utdanning, antall tidligere fødsler og tidligere dødfødsler. Disse dataene ble hentet fra skjema 1 og Partus.

\section{Statistikk}

Deskriptiv statistikk presenterer datamaterialet i gjennomsnitt, for de kontinuerlige variablene, og frekvens (antall og prosent) for de kategoriske. Internkonsistensreliabilitet i de forskjellige skjemaer måles ved hjelp av Cronbachs alfa. Ujusterte og justerte oddsratioer ble estimert i logistiske regre- 
sjonsmodeller. Statistisk signifikans ble definert ved $p$-verdi $<0,05$. Analysene ble foretatt med statistikkprogrammet SPSS, versjon 18

\section{Resultater}

Tabell 1 viser demografiske data i studien sammenliknet med alle fødsler på Akershus universitetssykehus i perioden 2009-11. Andelen av både spontanaborter og selvbestemte aborter var nærmest identisk i de selvrapporterte dataene med det som var registrert i sykehusets elektroniske fødejournaler i løpet av prosjektperioden (tab 2). Antallet pasienter som kom til ultralydundersøkelse ved sykehuset $(n=6244)$ var lavere enn datauttrekket fra fødejournalene $(\mathrm{n}=9$ 587). Dette skyldes at antallet fødsler økte i løpet av datainnsamlingsperioden pga. utvidet opptaksområde. I tillegg omfatter datauttrekket fra fødejournalene en litt lengre periode enn datainnsamlingen i Favn om fødselen-studien.

$8 \%(220 / 2753)$ av kvinnene rapporterte angst for å føde. Forekomsten av depresjon var 8,3\% (228/2 750), og forekomsten av angst var $8,8 \%$ (243/2 747). 4,4\% (120/2 744) av kvinnene rapporterte både angst og depresjon. Disse resultatene stemmer godt overens med tidligere analyser på det samme datamaterialet (20). Intern konsistens, målt ved Cronbachs alfa, var høy for alle psykometriske måleinstrumenter $(0,90$ for Wijma-skalaen, 0,84 for SCL-angstskalaen og 0,80 for EPDS). Disse resultatene tilfredsstiller kravene for akseptabel reliabilitet (30).

Blant kvinnene som hadde opplevd to eller flere spontanaborter, rapporterte 9,9\% angst for å føde, sammenliknet med 7,5\% blant dem som aldri hadde hatt spontanabort (ujustert oddsratio 1,4; $95 \% \mathrm{KI} 0,8-2,2$ ). Blant kvinner med to eller flere selvbestemte aborter hadde $11,7 \%$ angst for å føde, sammenliknet med 7,8\% av dem som aldri hadde tatt abort (ujustert OR 1,6; $95 \%$ KI 0,9-2,9) (tab 3). Når det ble justert for psykisk helsestatus, paritet, tidligere dødfødsler og sosiodemografiske faktorer, minsket oddsratioene for fødselsangst for både spontanabort og selvbestemt abort, og ingen av analysene nådde statistisk signifikans. Derimot var det en sterk assosiasjon mellom kontrollvariabelen psykisk helsestatus og fødselsangst. Kvinner som var plaget av angst eller depresjon, hadde en økt risiko for fødselsangst, særlig hvis de var plaget av både angst og depresjon samtidig (justert OR 12,6; $95 \%$ KI 8,1-19,8).

\section{Diskusjon}

Basert på resultatene fra denne studien blant 2753 gravide på Akershus universitetssykehus fant vi ingen assosiasjon mellom tidligere aborthistorie og fødselsangst. Blant de kvinnene som hadde fått utført to eller flere selvbestemte aborter, hadde en større andel angst for å føde enn blant dem som aldri hadde tatt
Tabell 1 Demografiske data i Favn om fødselen-studien sammenliknet med alle fødsler registrert i elektroniske fødejournaler (Partus) på Akershus universitetssykehus i perioden 2009-11

\begin{tabular}{|c|c|c|}
\hline & Favn om fødselen & Fødejournal \\
\hline Antall kvinner & 2753 & 9587 \\
\hline Alder (år), gjennomsnitt (SD) & $31,1 \quad(4,7)$ & 30,3 \\
\hline
\end{tabular}

\section{Sivilstatus, antall (\%)}

$\begin{array}{lrrrr}\text { Gift/samboer } & 2657 & (96,5) & 8964 & (93,5) \\ \text { Singel/enslig } & 73 & (2,7) & 551 & (5,7) \\ \text { Manglende informasjon } & 23 & (0,8) & 72 & (0,85)\end{array}$

Høyest fullførte utdanning, antall (\%)

$\begin{array}{lrrrrr}\text { Grunnutdanning og videregående utdanning } & 921 & (33,5) & 4483 & (46,8) \\ \text { Universitet/høyskole } & 1727 & (62,7) & 4478 & (46,7) \\ \text { Manglende informasjon } & 105 & (3,8) & 627 & (6,5)\end{array}$

Paritet, antall (\%)

Førstegangsfødende

$1369 \quad(49,7)$

Flergangsfødende

$1384(50,3)$

Dødfødsler, antall (\%)

$27 \quad(1,0)$

Tabell 2 Andel selvrapporterte aborter blant 2753 gravide i Favn om fødselen-studien sammenliknet med andelen registrerte aborter i elektroniske fødejournaler på Akershus universitetssykehus i perioden 2009-11 der totalt 9587 gravide var registrert

\begin{tabular}{|c|c|c|c|c|}
\hline & \multicolumn{2}{|c|}{ Spontane (\%) } & \multicolumn{2}{|c|}{ Selvbestemte (\%) } \\
\hline & Favn om fødselen & Fødejournal & Favn om fødselen & Fødejournal \\
\hline Ingen & 75,9 & 75,5 & 81,2 & 82,9 \\
\hline 1 abort & 16,8 & 17,6 & 14,8 & 13,1 \\
\hline 2 eller flere & 7,3 & 6,8 & 4,0 & 3,9 \\
\hline
\end{tabular}

abort, men forskjellene var ikke statistisk signifikante. Når det ble tatt høyde for psykisk helsestatus, forsvant denne forskjellen helt. Vi fant heller ingen sammenheng mellom spontanaborter og angst for å føde. Den faktoren som viste sterkest samvariasjon med fødselsangst var angst og depresjon, noe som også er i tråd med tidligere publiserte funn fra det samme datamaterialet (20). Tidligere resultater var imidlertid basert på 1642 kvinner, mens denne studien er basert på et større antall $(\mathrm{n}=2753)$.

En styrke i denne studien er at alle gravide kvinner som kom til rutineultralyd ble invitert til å delta. Tidligere studier er hovedsakelig basert på selekterte data fra kvinner som får oppfølging på grunn av fødselsangst $(7,9)$.

Wijma-skalaen er for tiden det hyppigst brukte instrumentet for å måle angst for å føde. Skalaen er funnet valid og reliabel $(8,22,31,32)$, og har gode psykometriske egenskaper. Vi har i denne studien brukt en terskelverdi på 85 , som er den mest brukte terskelverdien for å skille mellom kvinner med og uten fødselsangst (7). I noen artikler om ekstrem fødselsangst benytter man seg imidlertid av en terskelverdi på 100 $(8,11)$.

For noen kvinner kan selvbestemt abort være forbundet med skyld og skam (14), og en viss underrapportering $i$ våre selvrapporterte data kunne forventes. Andelen rapporterte aborter $\mathrm{i}$ denne studien er imidlertid nesten helt lik andelen registrerte aborter $\mathrm{i}$ sykehusets fødejournaler.

Det er mulig at deltakerne i studien er noe mer ressurssterke enn gjennomsnittet i populasjonen. I vår studie hadde $63 \%$ høyere utdanning, sammenliknet med $47 \%$ blant alle som fødte på sykehuset i prosjektperioden. Deltakerne var også noe eldre enn gjennomsnittet av alle som fødte på Akershus 
Tabell 3 Ujustert og justert oddsratio med $95 \%$ konfidensintervaller (KI) for angst for å føde i forhold til aborthistorie og psykisk helse blant 2753 gravide på Akershus universitetssykehus. Angst for å føde ble definert som W-DEQ > 85. Justert oddsratio innebærer justering for alder, sivilstand, utdanning, paritet og tidligere dødfødsler

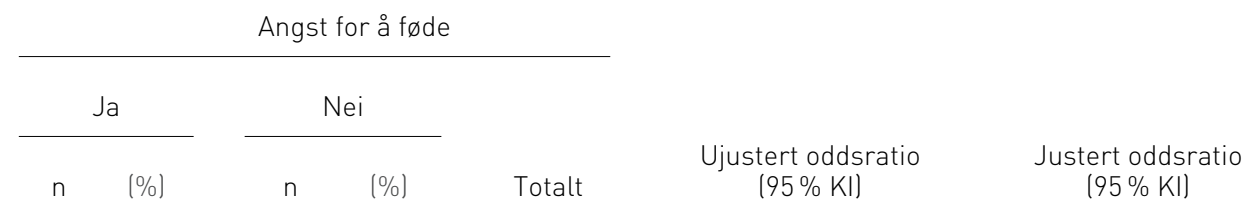

Spontanabort

$\begin{array}{lrrrrrrrrr}\text { Ingen } & 156 & (7,5) & 1933 & (92,5) & 2089 & 1,0 & 1,0 & & \\ 1 \text { tidligere } & 44 & (9,5) & 418 & (90,5) & 462 & 1,3 & (0,9-1,8) & 1,2 & (0,8-1,8) \\ 2 \text { eller flere } & 20 & (9,9) & 182 & (90,1) & 202 & 1,4 & (0,8-2,2) & 1,2 & (0,7-2,1)\end{array}$

Selvbestemt abort

\begin{tabular}{|c|c|c|c|c|c|c|c|c|c|}
\hline Ingen & 174 & $(7,8)$ & 2061 & $(92,2)$ & 2235 & 1,0 & & 1,0 & \\
\hline 1 tidligere & 33 & $(8,1)$ & 374 & $(91,9)$ & 407 & 1,0 & $(0,7-1,5)$ & 1,0 & $(0,6-1,5)$ \\
\hline 2 eller flere & 13 & $(11,7)$ & 98 & $(88,3)$ & 111 & 1,6 & $(0,9-2,9)$ & 1,1 & $(0,6-2,3)$ \\
\hline
\end{tabular}

\section{Psykisk helse}

\begin{tabular}{|c|c|c|c|c|c|c|c|c|c|}
\hline Ingen depresjon eller angst & 133 & $(5,5)$ & 2264 & $(94,5)$ & 2397 & 1,0 & & 1,0 & \\
\hline Angst & 13 & $(10,7)$ & 108 & $(89,3)$ & 121 & 2,0 & $(1,1-3,7)^{1}$ & 2,5 & $(1,3-4,7)^{1}$ \\
\hline Depresjon & 29 & $(27,4)$ & 77 & $(72,6)$ & 106 & 6,4 & $(4,0-10,2)^{2}$ & 6,9 & $(4,2-11,3)^{2}$ \\
\hline Både angst og depresjon & 44 & $(36,7)$ & 76 & $(63,3)$ & 120 & 9,9 & $(6,5-14,9)^{2}$ & 12,6 & $(8,1-19,8)^{2}$ \\
\hline Manglende informasjon & & & & & 9 & & & & \\
\hline
\end{tabular}

$1 P<0,05 \quad 2 P<0,001$

universitetssykehus i løpet av prosjektperioden (31,1 år mot 30,3 år). Kun kvinner som behersket norsk godt nok til å fylle ut et spørreskjema deltok, noe som også kan være en mulig svakhet ved undersøkelsen.

Graden av assosiasjon vil ofte forandre seg når flere faktorer trekkes inn i sammenhengen slik at den bivariate analysen justeres. I denne studien fant vi en tendens til at kvinner som hadde tatt to eller flere aborter, utviklet angst for å føde. Denne tendensen forsvant når det ble justert for psykisk helse i de multivariate analysene. Våre resultater samsvarer med funn fra tidligere studier som har vist at en større andel av dem som har tatt abort, har psykiske problemer enn av dem som ikke har tatt abort $(17,18)$. Aborthistorie har vært assosiert med skyld, skam og dårlig psykisk helse, samtidig som psykisk helse er en risikofaktor for fødselsangst (20). I tillegg til psykisk helse har vi i denne studien tatt høyde for paritet, tidligere dødfødsler og sosiodemografiske faktorer. Allikevel kan det finnes konfunderende faktorer som vi ikke har hatt mulighet til å kontrollere for.

Abort angår mange kvinner i Norge (15). Mulige konsekvenser for kommende svangerskap er derfor viktig informasjon, ikke bare for kvinnene selv, men også for helsepersonell. Tidligere studier har vist at kvinner som har hatt obstetriske komplikasjoner $\mathrm{i}$ forbindelse med fødsel, har en økt risiko for å utvikle fødselsangst i påfølgende svangerskap $(8,9)$. En abort kan for noen også oppleves som skremmende, enten den er selvbestemt eller spontan. Våre resultater tyder imidlertid ikke på at slike erfaringer fører til økt risiko for fødselsangst.

\section{Tone Breines Simonsen (f. 1963)}

er jordmor, prosjektkoordinator og masterstudent.

Forfatter har fylt ut ICMJE-skjemaet og oppgir ingen interessekonflikter.

\section{Astrid Klopstad Wahl (f. 1963)}

er professor og forsker på livskvalitet.

Forfatter har fylt ut ICMJE-skjemaet og oppgir ingen interessekonflikter.

\section{Siri Vangen (f. 1954)}

er dr.med./spesialist i fødselshjelp og kvinnesykdommer og leder for Nasjonal kompetansetjeneste for kvinnehelse.

Forfatter har fylt ut ICMJE-skjemaet og oppgir ingen interessekonflikter.

\section{Malin Eberhard-Gran (f. 1961)}

er dr.med. og seniorforsker. Hun er prosjektleder for Favn om fødselen-studien på Akershus universitetssykehus og er involvert i flere prosjekter der man anvender data om svangerskap og fødsel.

Forfatter har fylt ut ICMJE-skjemaet og oppgir ingen interessekonflikter.

Litteratur

1. Kolås T, Hofoss D, Daltveit AK et al. Indications for cesarean deliveries in Norway. Am J Obstet Gynecol 2003; 188: 864-70

2. Saisto T, Halmesmäki E. Fear of childbirth: a neglected dilemma. Acta Obstet Gynecol Scand 2003; 82: $201-8$.

3. Sjögren B, Thomassen P. Obstetric outcome in 100 women with severe anxiety over childbirth. Acta Obstet Gynecol Scand 1997; 76: 948-52.

4. Adams SS, Eberhard-Gran M, Sandvik AR et al. Mode of delivery and postpartum emotional distress: a cohort study of 55,814 women. BJOG 2012; 119: 298-305.

5. Sydsjö G, Angerbjörn L, Palmquist $S$ et al. Secondary fear of childbirth prolongs the time to subsequent delivery. Acta Obstet Gynecol Scand 2012; e-publisert 16.8.2012.

6. Barnett B, Parker G. Possible determinants, correlates and consequences of high levels of anxiety in primiparous mothers. Psychol Med 1986; 16: 177-85. 
7. Ryding EL, Wijma B, Wijma K et al. Fear of childbirth during pregnancy may increase the risk of emergency cesarean section. Acta Obstet Gynecol Scand 1998; 77: 542-7.

8. Rouhe H, Salmela-Aro K, Halmesmäki E et al. Fear of childbirth according to parity, gestational age, and obstetric history. BJOG 2009; 116: 67-73.

9. Saisto T, Ylikorkala O, Halmesmäki E. Factors associated with fear of delivery in second pregnancies. Obstet Gynecol 1999; 94: 679-82.

10. Storksen HT, Garthus-Niegel S, Vangen S et al. The impact of previous birth experiences on maternal fear of childbirth. Acta Obstet Gynecol Scand 2012; e-publisert 24.12.2012.

11. Heimstad R, Dahloe R, Laache I et al. Fear of childbirth and history of abuse: implications for pregnancy and delivery. Acta Obstet Gynecol Scand 2006; 85: 435-40.

12. Eberhard-Gran M, Slinning K, Eskild A. Fear during labor: the impact of sexual abuse in adult life. J Psychosom Obstet Gynaecol 2008; 29: 258-61.

13. Coleman PK, Reardon DC, Strahan T et al. The psychology of abortion: A review and suggestions for future researc. Psychol Health 2005; 20: 237-71.

14. Broen AN, Moum T, Bödtker AS et al. Predictors of anxiety and depression following pregnancy termination: a longitudinal five-year follow-up study. Acta Obstet Gynecol Scand 2006: 85: 317-23.

15. Rapport om svangerskapsavbrudd for 2011. Oslo: Nasjonalt folkehelseinstitutt, 2012. www.fhi.no/ eway/default.aspx? pid=233\&trg=MainLeft 5583\& MainArea 5661 =5583:0:15,1359:1:0:0::0: $0 \&$ Main Left $5583=5603: 97908 \cdot: 1 \cdot 5585 \cdot 1 \cdots 0: 0$ (8.1.2013)

16. Veileder i generell gynekologi 2009. Oslo: Norsk gynekologisk forening. Den norske legeforening. 2009.
17. Broen AN, Moum T, Bødtker AS et al. The course of mental health after miscarriage and induced abortion: a longitudinal, five-year follow-up study. BMC Med 2005; 3: 18

18. Munk-Olsen T, Laursen TM, Pedersen CB et al. Induced first-trimester abortion and risk of menta disorder. N Engl J Med 2011; 364: 332-9.

19. Academy of Medical Royal Colleges. Induced abortion and mental health. 2011. www.nccmh.org.uk/ publications SR abortion in MH.html (8.1.2013).

20. Storksen HT, Eberhard-Gran M, Garthus-Niegel S et al. Fear of childbirth; the relation to anxiety and depression. Acta Obstet Gynecol Scand 2012; 91: 237-42.

21. Adams SS, Eberhard-Gran M, Eskild A. Fear of childbirth and duration of labour: a study of 2206 women with intended vaginal delivery. BJOG 2012 119: 1238-46.

22. Wijma K, Wijma B, Zar M. Psychometric aspects of the W-DEQ; a new questionnaire for the measurement of fear of childbirth. J Psychosom Obstet Gynaecol 1998; 19: 84-97.

23. Cox JL, Holden JM, Sagovsky R. Detection of postnatal depression. Development of the 10-item Edinburgh Postnatal Depression Scale. Br Psychiatry 1987; 150: 782-6.

24. Cox JL, Chapman G. Murray D et al. Validation of the Edinburgh postnatal depression scale (EPDS) in non-postnatal women. J Affect Disord 1996; 39 : $185-9$

25. Eberhard-Gran M, Eskild A, Tambs K et al. The Edinburgh Postnatal Depression Scale: validation in a Norwegian community sample. Nord J Psychiatry $2001 ; 55: 113-7$.

26. Eberhard-Gran M, Tambs K, Opjordsmoen S et al. A comparison of anxiety and depressive symptomatology in postpartum and non-postpartum mothers. Soc Psychiatry Psychiatr Epidemiol 2003. 38: $551-6$.

27. Mathiesen KS, Tambs K, Dalgard OS. The influence of social class, strain and social support on symptoms of anxiety and depression in mothers of toddlers. Soc Psychiatry Psychiatr Epidemiol 1999; 34: $61-72$.

28. Nettelbladt P, Hansson L, Stefansson CG et al. Test characteristics of the Hopkins Symptom Check List-25 (HSCL-25) in Sweden, using the Present State Examination (PSE-9) as a caseness criterion. Soc Psychiatry Psychiatr Epidemiol 1993 28: $130-3$

29. Sandanger I, Moum T, Ingebrigtsen $G$ et al. Concordance between symptom screening and diagnostic procedure: the Hopkins Symptom Checklist-25 and the Composite International Diagnostic Interview I. Soc Psychiatry Psychiatr Epidemiol 1998: 33: $345-54$

30. Terwee CB, Bot SD, de Boer MR et al. Quality criteria were proposed for measurement properties of health status questionnaires. J Clin Epidemiol 2007: 60: 34-42.

31. Garthus-Niegel S, Størksen HT, Torgersen L et al. The Wijma Delivery Expectancy/Experience Questionnaire: a factor analytic study. J Psychosom Obstet Gynaecol 2011; 32: 160-3.

32. Johnson R, Slade P. Does fear of childbirth during pregnancy predict emergency caesarean section? BJOG 2002; 109: 1213-21.

Mottatt 3.7. M2012, første revisjon innsendt 17.10 2012, godkjent 1.1. 2013. Medisinsk redaktør Kristin Viste. 